\title{
KALIMANTAN
}

'Tournees met een medisch doel', zo omschrijft Arnoud H. Klokke zijn reizen die hij maakte tussen 1950 en 1952 vanuit het centrale ziekenhuis in Kuala Kupuas in het zuiden van Midden-Kalimantan.

Als pas afgestudeerd arts aan de Universiteit Leiden werd Klokke in 1949 door de medische zending van de Nederlands Hervormde Kerk uitgezonden naar Centraal Borneo (nu: Kalimantan). Als zendingsarts in dienst van de Indonesische regering reisde hij rond 1950 langs de grote rivieren van Midden-Kalimantan diep het binnenland in, waar hij de dorpen van de Ngaju en Ot Danum bezocht. Hier maakte hij veel foto's van het bijzondere cultureel erfgoed van deze Dayakgroepen. Dankzij de pas verschenen tweetalige publicatie van het boek Langs de rivieren van Midden-Kalimantan 1 Along the rivers of Central Kalimantan kunnen we middels deze fascinerende foto's kennisnemen van de materiële cultuur van deze bevolkingsgroepen in de dorpen langs de rivieren Kaupuas, Kahayan en Rongan in de tegenwoordige provincie Midden-Kalimantan, zestig jaar geleden.

Het boek is gestructureerd ingedeeld. In het voorwoord zet Francine Brinkgreve, conservator Insulair Zuidoost-Azië in Museum Volkenkunde, uiteen dat de expeditiefoto's van Klokke de aanleiding vormden voor deze publicatie. Vervolgens geeft zij een heldere schets van de achtergrond van de etniciteit en religie van de in het boek centraal staande bevolkingsgroepen en hoe het boek in een geografische ordening is opgebouwd. Dat wil zeggen: vanaf de dorpen in de benedenstroomse gebieden tot aan die in het stroomopwaarts gelegen bovenland.

In de inleiding geeft Arnoud Klokke persoonlijke achtergrondinformatie over de totstandkoming van de gepresenteerde fotoreportage. Hij uit zijn vreugde dat hij op hogere leeftijd de kans heeft gekregen om met deze publicatie zijn dankbaarheid te tonen voor de wijze waarop de Dayakse gemeenschap hem in haar midden heeft opgenomen. Familielid Rebke Klokke krijgt zeer terecht ook een pluim van haar oudoom. Als fotograaf heeft zij met gevoel voor de context de lay-out en digitalisering van de oude negatieven verzorgd.

Tijdens zijn tournees ontmoette Klokke islamitisch-Maleisische gemeenschappen en christelijke Dayaks, waarvan nu velen ook tot de islam zijn bekeerd. Op die reizen in de jaren ' 50 van de vorige eeuw zag hij ook veel uitingen van materiële cultuur, die verband hielden met de oorspronkelijke Kaharingan religie en tradities van de Dayak. Dr. Marko Mahin, zelf een Dayak, beschrijft in zijn artikel in dit boek de religieuze veranderingen die hebben plaatsgevonden en de aanpassingen die de traditionele Kaharingan religie in de Republiek Indonesië heeft ondergaan, sinds de tijd van de tournees van Klokke. Zo concludeert Mahin dat oude ritureken binnen deze 3 03:00:32PM 


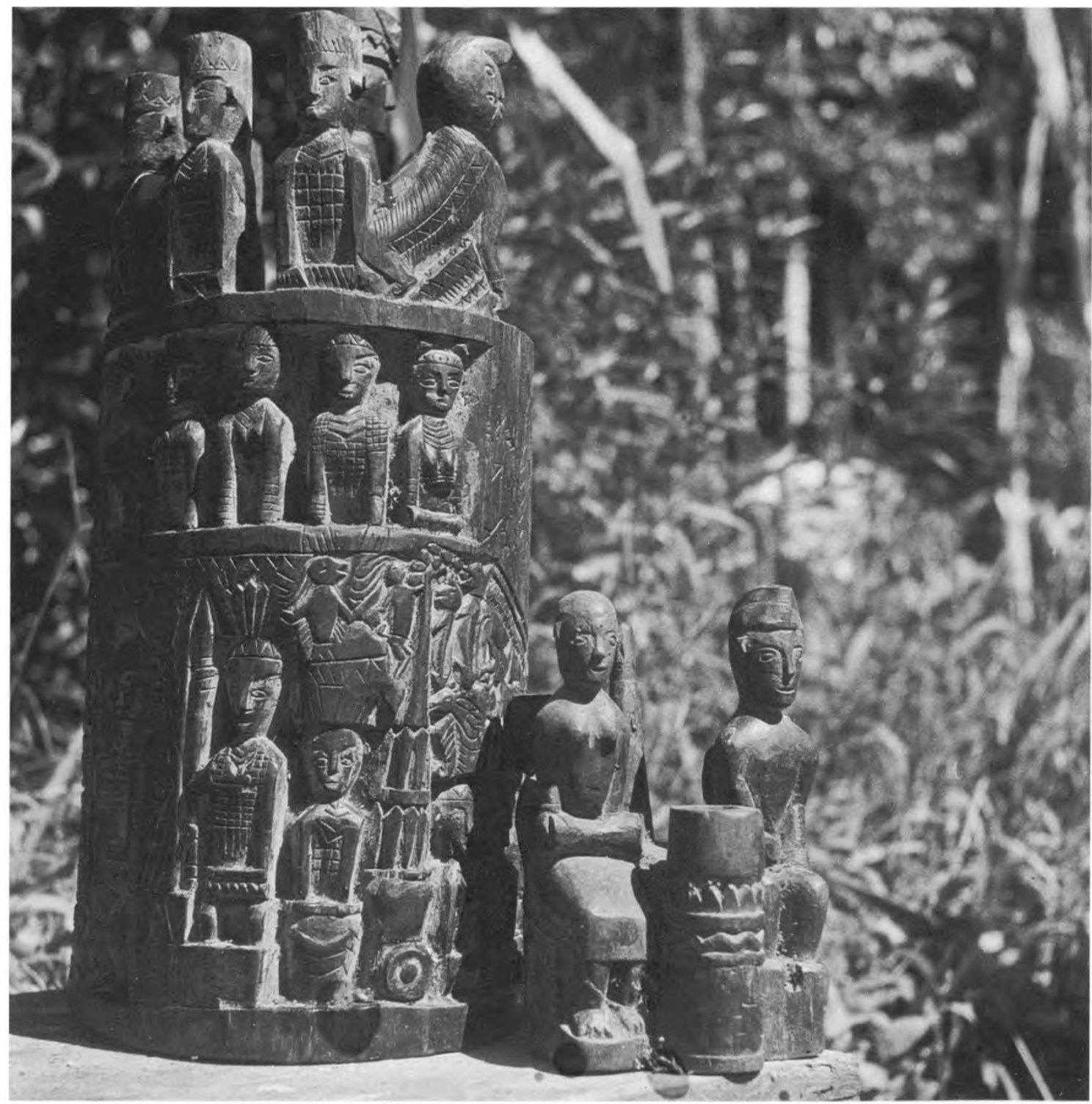

Afb. 2. Hampatong. Een

gesneden houten blok met

menselijke figuren, sommige

in reliëf, h. $40 \mathrm{~cm}$., d. 25

cm. Dit was een voorwerp

van devotie bij

huisceremoniën. Een

dergelijk beeld is door

Arnoud Klokke verworven en

bevindt zich in de Collectie

Klokke in Museum Volken-

kunde (inv.nr. 4861-1). 
Kaharingan nog steeds belangrijke elementen vormen binnen de cultuur van de Ngaju Dayak. Een voorbeeld is het heilige tiwah ritueel. Dit ritueel, dat is bedoeld om de ziel van de overledene te begeleiden naar de bovenwereld, is anno 2012 nog springlevend en van belang bij de ontwikkeling van cultuur en identiteit van de Dayakbevolking. Verschillende objecten die bij dit ritueel worden ingezet zijn in dit boek opgevoerd en van informatieve bijschriften voorzien.

Naast het fotograferen tijdens zijn expedities had Arnoud Klokke nog een ander doel, namelijk het verzamelen van voorwerpen, zoals gedecoreerde matten, bamboe kokers, en maskers. Ofwel hij kocht deze voorwerpen van de plaatselijke bevolking, of hij ontving ze als geschenk, als dank voor de medische behandeling die hij verstrekte. Veel van deze voorwerpen heeft Klokke tussen 1951 en 2011 geschonken of verkocht aan Museum Volkenkunde. $\mathrm{Zij}$ zijn vooral waardevol omdat de herkomst van de voorwerpen, soms zelfs de maker ervan, goed is gedocumenteerd. Dit boek vormt een mooie aanvulling op deze collectie. In een apart hoofdstuk zijn van de 55 objecten in de Collectie Klokke vier voorwerpen afgebeeld en afzonderlijk beschreven.

Langs de rivieren van Midden-Kalimantan is vooreerst een fotoboek met prachtige informatieve zwart-wit foto's. De uitgebreide bijschriften geven de lezer onschatbaar waardevolle extra informatie. Beeld en tekst tezamen maken in één oogopslag inzichtelijk hoe rijk de materiële cultuur van de Ngaju en Ot Danum zestig jaar geleden was. Boeken als deze hebben een grote cultuurhistorische en wetenschappelijke betekenis. Zo'n publicatie met het hierin vastgelegde cultureel erfgoed maakt ons bewust van de cultuur en geschiedenis van deze bevolkingsgroepen.

- Arnoud H. Klokke, Langs de rivieren van Midden-Kalimantan: Cultureel erfgoed van de Ngaju en Ot Danum Dayak / Along the rivers of Central Kalimantan: Cultural heritage of the Ngaju and Ot Danum Dayak (met een bijdrage van Marko Mahin), Museum Volkenkunde \& C. Zwartenkot Art Books, Leiden, 2012.

Paperback, 176 blz., 200 zwart-wit foto's, 3 kaarten, verklarende woordenlijst, bibliografie, ISBN 978-90-5450-012-4, € 24,50.

- Rosalien van der Poel is onder andere als buitenpromovendus verbonden aan het Leiden University Centre of Arts in Society (LUCAS) van de Universiteit Leiden, en als associate researcher betrokken bij Museum Volkenkunde. 


\section{Vereniging van Vrienden der Aziatische Kunst}

www.vvak.nl

ERELID

Dr. J. Fontein

BESTUUR

Mr. J.M. Boll, voorzitter

Ir. A.A. Holst, lid

Mw. drs. R.H.M. van der Poel, secretaris

Mw. drs. R.E. Roskam, lid

Drs. T.T. Wen, penningmeester

RAAD VAN ADVIES

Mr. W.L.J. Bröcker

Prof.dr. C.J.A. Jörg

Drs. H.E. Kreijger

Mr. E.M.W. de Lange

Mr. drs. A. Ott

J. Polak

Mw. dr. C.E. van Rappard-Boon

J.J.N. Rost Onnes

Mw. dr. R.L. Steenbergen

CORPORATE MEMBER / SPONSOR

Ottema-Kingma Stichting Leeuwarden

International Institute for Asian Studies (IIAS)

Mw. mr. E. Veder-Smit

\section{Lidmaatschap}

- Gewoon lidmaatschap: $€$ 60,- per kalenderjaar

- Gewoon lidmaatschap (inclusief partner): $€$ 90,- per kalenderjaar

- Jongerenlidmaatschap ( $\mathrm{t} / \mathrm{m} 25$ jaar): $€ 25,-$ per kalenderjaar

- Sponsor/corporate member: (tenminste) $€ 600,-$ per kalenderjaar

Het lidmaatschap van de Vereniging loopt van 1 januari tot en met 31 december. Opzegging van het lidmaatschap kan alleen schriftelijk via het bestuur (vvak@denboerenvink.nl). Opzegging voor een komend jaar dienen vóór 31 december van het lopende jaar door het bestuur ontvangen te zijn. Wanneer het lidmaatschap in de loop van het verenigingsjaar wordt beëindigd, blijft de bijdrage voor het hele jaar verschuldigd.

\section{Als WVAK-lid}

- ontvangt u het tijdschrift Aziatische Kunst

- blijft u goed op de hoogte van tentoonstellingen, beurzen en veilingen op het gebied van Aziatische kunst

- wordt u uitgenodigd voor lezingen en speciale bijeenkomsten

- krijgt u een lidmaatschapskaart, waarmee u gratis toegang heeft tot het Rijksmuseum Amsterdam

\section{Ledenadministratie}

Jac's den Boer en Vink bv

Postbus 43 - 2850 AA Haastrecht

T: 0182501696

E:vvak@denboerenvink.nl

\section{Secretariaat VVAK}

Eline van den Berg

p/a Rijksmuseum Amsterdam

Frans van Mierisstraat $92-1071$ RZ Amsterdam

E: secretariaat@vvak.nl

\section{Advertenties}

Om te adverteren in Aziatische Kunst kunt $u$ contact opnemen met de heer drs. T.T. Wen, penningmeester, e-mail:wentt@xs4all.nl

\section{Bankrekeningnummer}

ING 188285, ten name van Vereniging van Vrienden der Aziatische Kunst, Den Haag.

\section{Kamer van Koophandel}

De Vereniging is ingeschreven bij de Kamer van Koophandel in Amsterdam, onder nummer 40.531.260.

\section{ANBI}

De Vereniging heeft de status van een Algemeen Nut Beogende Instelling. Brill. com04/26/2023 03:00:32PM 